\title{
ResearchArticle
}

\section{Growth assessment of buckwheat (Fagopyrum species) - A source of fodder}

\author{
SHAYAT KUMAR
}

\section{SUMMARY}

A field experiment was conducted with five local species of buckwheat to study the diversity pattern based on quantitative and qualitative characters during the November 2011 to April 2012. There exists significant variation among the buckwheat genotypes for all the parameters studied. Days to 50 per cent flowering, plant height, number of leaves, fresh weight of leaves, fresh weight of stem were found to contribute maximum towards genetic divergence among the buckwheat genotypes. Considering diversity pattern and other agronomic performance, F. tataricum out yielded other three species under the field conditions.

Key Words : Buckwheat (F. esculentum, F. kashmirianum, F. esculentum and F. sagittatum.), Fodder, Qualitative traits, Quantitative traits, Yield

How to cite this article : Kumar, Shayat (2017). Growth assessment of buckwheat (Fagopyrum species) - A source of fodder. Internat. J. Plant Sci., 12 (1): 61-63, DOI: 10.15740/HAS/IJPS/12.1/61-63.

Article chronicle : Received : 28.08.2016; Revised : 21.11.2016; Accepted : 17.12.2016

\section{AUTHOR FOR CORRESPONDENCE}

SHAYAT KUMAR, Department of Botany, Govt. College For Women,

Parade, JAMMU (J\&K) INDIA 